\title{
Optimization of multiple performance characteristics in turning using Taguchi's quality loss function: An experimental investigation
}

\author{
Ashok Kumar Sahoo* and Tanmaya Mohanty
}

\begin{tabular}{l} 
School of Mechanical Engineering, KIIT \\
\hline C H R O N I C L E \\
\hline Article history: \\
Received January 12012 \\
Received in revised format \\
April 152013 \\
Accepted April 152013 \\
Available online \\
April 152013 \\
\hline Keywords: \\
Cutting force \\
Chip reduction coefficient \\
Taguchi's loss function \\
Orthogonal array
\end{tabular}

A B S T R A C T
Cutting force and chip reduction coefficient is the important index of machinability as it
determines the power consumption and amount of energy invested in machining actions. It is
primarily influenced by process parameters like cutting speed, feed and depth of cut. This paper
presents the application of Taguchi's parameter design to optimize the parameters for individual
responses. For multi-response optimization, Taguchi's quality loss function approach is proposed.
In the present investigation, optimal values of cutting speed, feed and depth of cut are determined
to minimize cutting force and chip reduction coefficient during orthogonal turning. The
effectiveness of the proposed methodology is illustrated through an experimental investigation in
turning mild steel workpiece using high speed steel tool.

\section{Nomenclature}

V Cutting speed

f Feed

d Depth of cut

$\mathrm{Pz} \quad$ Cutting force

$a_{2} \quad$ Chip thickness after cut

$\mathrm{a}_{1} \quad$ Uncut chip thickness

DF Degrees of freedom

SS Sum of squares

MS Mean square

\section{Greek symbol \\ $\zeta \quad$ Chip reduction coefficient}

\footnotetext{
* Corresponding author.

E-mail: aklala72@gmail.com (A.K. Sahoo)

(C) 2013 Growing Science Ltd. All rights reserved. doi: $10.5267 / j$.jijiec.2013.04.002
} 


\section{Introduction}

Turning is the most essential and common process of producing finished product with the help of cutting tools that moved past to the workpiece in a machine tool. The purpose is to remove extra material from the preformed parts. The two basic types of cutting using a single point cutting tool are the orthogonal (2D) and oblique cutting (3D). In orthogonal cutting, the cutting edge of the tool remains normal to the direction of feed and cutting velocity vector. The direction of chip flow velocity is normal to the cutting edge of the tool. In most of the machining processes, following type of chips are obtained: Continuous chips, continuous chips with built-up-edge and discontinuous chips. The chip thickness $\left(a_{2}\right.$ ) usually becomes larger than the uncut chip thickness $\left(_{1}\right.$ ) in machining because of compression of the chip ahead of the tool, frictional resistance to chip flow and lamellar sliding (Piispannen, 1948). Chip reduction coefficient, $\zeta$ is defined as the ratio of the chip thickness after $\left(\mathrm{a}_{2}\right)$ and before cut $\left(\mathrm{a}_{1}\right)$. Larger value of $\zeta$ attributed to more thickening i.e., more effort in terms of forces or energy is invested to perform the machining operation. Therefore, it is always essential to reduce $\mathrm{a}_{2}$ or $\zeta$ without sacrificing productivity. Therefore, chip reduction coefficient is taken as the important index of machinability in machining work. Again, the cutting force also plays vital role in machining as it determines the amount of power consumption. Thus, the machining operation is performed in such a way that effectiveness, efficiency and overall economy are achieved. Machining of any work material by given tool depend on the machinability characteristics of the tool-work material. Machinability is defined as ability of being machined or ease of machining.

Machinability is usually judged by (i) cutting temperature which affects product quality and cutting tool performance, (ii) pattern and mode of chip formation, (iii) magnitude of the cutting forces which affects power requirement, dimensional accuracy and vibration, (iv) surface finish, and (v) tool wear and tool life (Dhar et al., 2006). The optimized process parameter is also important task in turning to select cutting parameters for achieving high cutting performance. In the past, several optimization methods for turning operations have been documented. Davim (2001) used Taguchi technique for surface roughness in turning. Multiple linear regression model was developed taking cutting velocity, feed and depth of cur as input parameters. Finally, confirmation test was performed to validate the results. The results induced less error when it was compared with the experiment results. Davim (2003) used Taguchi technique for surface roughness, tool wear and power consumption in turning MMC with PCD cutting tools.

Jayant (2008) outlined the Taguchi optimization methodology to optimize cutting parameters in turning when machining hardened steel AISI 4140 with carbide insert tool under semifinishing and finishing conditions of high speed cutting. Main effects of process parameters on the quality characteristics analyzed and obtained an optimal combination of process parameters. Aggarwal et al. (2008) presented the findings of an experimental investigation into the effects of cutting speed, feed rate, depth of cut, nose radius and cutting environment in CNC turning of AISI P-20 tool steel using response surface methodology (RSM) and Taguchi's technique. $\mathrm{L}_{27}$ orthogonal array and face centered central composite design have been used for conducting the experiments. Taguchi's technique as well as 3D surface plots of RSM revealed that cryogenic environment is the most significant factor in minimizing power consumption followed by cutting speed and depth of cut. The effects of feed rate and nose radius were found to be insignificant compared to other factors. Though both the techniques predicted near similar results, RSM technique seems to have an edge over the Taguchi's technique.

Kirby et al. (2006) presented an application of the Taguchi parameter design method to optimize the surface finish in a turning operation. The control parameters for this operation included: spindle speed, feed rate, depth of cut and tool nose radius. A confirmation run was used to verify the results, which indicated that this method was both efficient and effective in determining the best turning parameters for the optimal surface roughness. Gauri and Chakraborty (2009) utilized principal component analysis 
(PCA)-based approach for multi response optimization. It was observed that the PCA-based optimization could give better results than the constrained optimization and MRSN ratio-based methods, which could be attributed to the fact that the possible correlation among the multiple responses is taken care in the PCA-based approach. Yang and Chen (2001) studied Taguchi method and $\mathrm{L}_{18}$ orthogonal array to optimize surface roughness in end milling operation. It was found that Taguchi parameter design could provide a systematic procedure, which could effectively and efficiently identify the optimum surface roughness in the process control of individual end milling machines. Sukthomya and Tannock (2005) presented an application of Taguchi's Design of Experiments to identify the optimum setting of NN parameters in a multilayer perceptron (MLP) network trained with the back propagation algorithm. Nalbant et al. (2007) used Taguchi method to find the optimal cutting parameters for surface roughness in turning. The orthogonal array, the signal-to-noise ratio and analysis of variance are employed to study the performance characteristics in turning operations of AISI 1030 steel bars using TiN coated tools. Three cutting parameters namely, insert radius, feed rate and depth of cut are optimized with considerations of surface roughness.

Tosun and Ozler (2004) presented an investigation on the optimization and the effect of cutting parameters on multiple performance characteristics (tool life and surface roughness) in hot turning operations. A plan of experiments based on the Taguchi method was designed. The results showed that cutting speed and feed rate were the dominant variables on multiple cutting performance characteristics. An optimum parameter combination was obtained by using statistical analysis. Singh and Kumar (2006) obtained an optimal setting of turning process parameters (cutting speed, feed rate and depth of cut) for the feed force when machining EN24 steel with TiC-coated tungsten carbide inserts. The effects of the selected turning process parameters on feed force and the subsequent optimal settings of the parameters were accomplished using Taguchi's parameter design approach. The results indicated that the selected process parameters could significantly affect the selected machining characteristics. Palanikumar (2006) discussed the use of Taguchi's method and Pareto ANOVA analysis for optimizing the cutting parameters in turning glass fiber reinforced plastic (GFRP) composites using a poly crystalline diamond (PCD) tool for minimizing surface roughness. The cutting parameters evaluated were cutting speed, feed rate and depth of cut. An $\mathrm{L}_{27}$ orthogonal array, signal to noise ratio and Pareto ANOVA analysis were used to analyze the effect of cutting parameters and its interactions. The experimental results suggested that the most significant process parameter was feed rate followed by cutting speed. The study showed that the Taguchi method and Pareto ANOVA were suitable for optimizing the cutting parameters with the minimum number of trials.

It was shown from the literature study that the use of the parameter design of the Taguchi method could greatly simplify the optimization procedure for determining the optimal cutting parameters in turning operations in a machine shop. Most published literature cited Taguchi approach for optimization of single performance characteristics. A very little research has been observed for multi-response optimization of process parameters utilizing Taguchi approach. In this present work, an attempt has been made for optimization of multiple performance characteristics in orthogonal turning operation. Thus, the paper is organized in the following manners. An overview of parameter design by Taguchi method and for simultaneous optimization for multi-responses using Taguchi's quality loss function is described first. The experimental details for orthogonal turning and optimization of individual performance characteristics like cutting force and chip reduction coefficient is analyzed next. Finally, the optimal cutting parameters for multiple performance characteristics using Taguchi's quality loss function are determined with different cases and validated through some confirmation runs.

\section{Methodology}

Taguchi (1990) design of experiment is robust and coupled with orthogonal arrays to study the entire parameter space with fewer numbers of experimental runs. This method utilizes loss function to calculate the deviation between the experimental value and the desired value. The loss function is then 
transformed into a signal-to-noise $(\mathrm{S} / \mathrm{N})$ ratio. Taguchi recommends three categories of performance characteristics for the analysis of $\mathrm{S} / \mathrm{N}$ ratio. They are the lower-the-better, the higher-the-better, and the nominal-the-better (Ross 1988). The mean $\mathrm{S} / \mathrm{N}$ ratio for each level of process parameters of performance characteristics is found out and larger $\mathrm{S} / \mathrm{N}$ ratio yielded the better performances. The optimal combination of process parameter is obtained taking higher $\mathrm{S} / \mathrm{N}$ ratios (Phadke, 1989). Finally, the optimal parameters are verified by some confirmation run to predict the improvement. In this paper, Taguchi parameter design is adopted to obtain optimal parameter in turning. For multi-response optimization problem, Taguchi parameter design approach was not applied directly. A normalized loss function approach is implemented first. To illustrate this approach, the loss function is first normalized to each performance characteristics. It is the ratio of loss function for the $i^{\text {th }}$ performance characteristics in the $j^{\text {th }}$ experiment to the average loss function for the $i^{\text {th }}$ performance characteristics.

$S_{i j}=\frac{L_{i j}}{\bar{L}_{i}}$.

The loss function for lower-the-better characteristics is expressed as follows,

$L_{i j}=\frac{1}{n} \sum_{k=1}^{n} y_{i j k}^{2}$,

where $y_{i j k}$ is the experimental value of the $i^{\text {th }}$ performance characteristics in the $j^{\text {th }}$ experiment at the $k^{\text {th }}$ test and $n$ is the number of tests. Then, a weighting method is adopted to evaluate the importance of each normalized loss function.

The total loss function is calculated based on the weighting method.

$T L_{j}=\sum_{i=1}^{m} W_{i} S_{i j}$,

where $W i$ is the weighting factor for the $i^{t h}$ performance characteristics and $m$ is the number of performance characteristics. The total loss function is then converted into a multi-response $\mathrm{S} / \mathrm{N}$ ratio (MRSN) as follows,

$\eta_{j}=-10 \log \left(T L_{j}\right)$

Multi-response $\mathrm{S} / \mathrm{N}$ ratio is then analyzed like the traditional Taguchi technique and optimal levels of process parameters is obtained. Finally, the optimal parameters are verified by confirmation run.

\section{Experimental procedure and results}

For the experimental investigations, test samples of mild steel (AISI 1040) were used. The diameter of workpiece was $47 \mathrm{~mm}$ and $300 \mathrm{~mm}$ length.

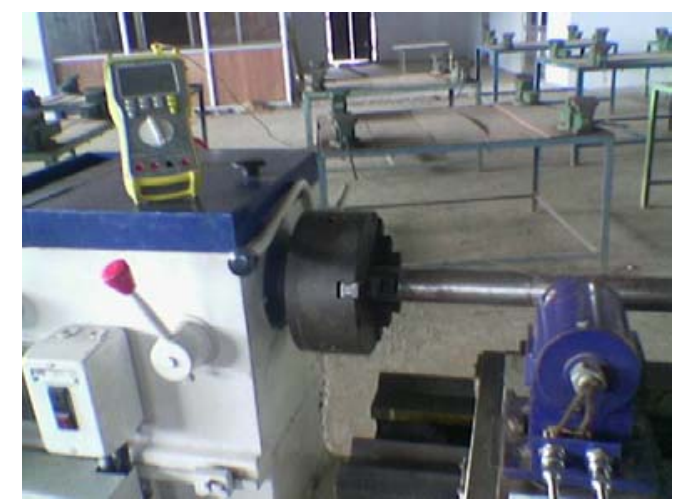

(a)

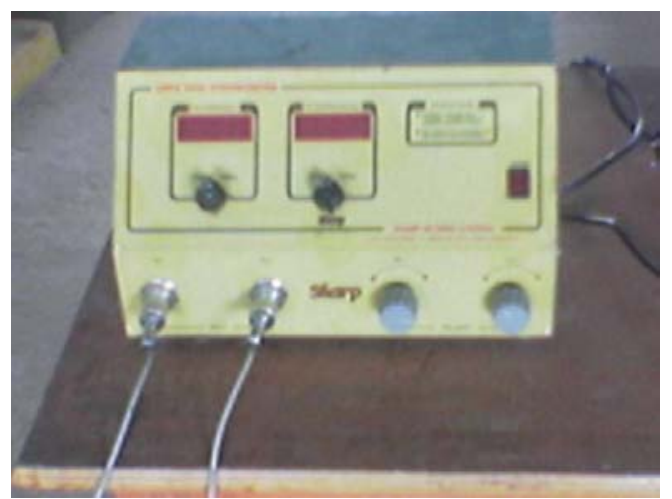

(b)

Fig. 1. Experimental setup (a) Turning tool dynamometer (b) Display channel for turning forces 
The skin layer was removed from the workpiece prior to experiment. The orthogonal turning experiment has been performed by a three jaw chuck center lathe (manufactured by $\mathrm{M} / \mathrm{s}$ Pathak engineering co, India) of maximum $1390 \mathrm{rpm}$ using commercially available HSS cutting tool (Miranda). The machining performances to be measured are cutting force and chip reduction coefficient in turning operation under dry environment. The cutting force is measured through a twodimensional strain gauge type turning dynamometer. The experimental setup is shown in Fig. 1. The chips are collected and measured by digital caliper to evaluate the chip reduction coefficient in this study. The chip reduction coefficient is determined by the ratio of $a_{2} / f$ where $a_{2}$ and $f$ are the chip thickness and feed respectively.

Next step is to select an appropriate orthogonal array for the experiments. As each process parameter has three levels, two degrees of freedom occur for each parameter. Therefore, total of six degrees of freedom is available for three process parameters neglecting interaction between the parameters in turning operation. In general, the degrees of freedom should be greater than or at least equal to those for the process parameters for selection of appropriate orthogonal array. In the present study, an $\mathrm{L}_{9}$ orthogonal array was used which consists of four columns with nine rows and can handle three-level process parameters. Each process parameter is assigned to a column and only nine experiments are essentially required using $\mathrm{L}_{9}$ orthogonal array.

The controllable process parameters and their levels chosen are summarized in Table 1. The experimental layout for the $\mathrm{L}_{9}$ orthogonal array with assigned process parameter is shown in Table 2 . Since the three process parameter is available for the study, one column of the $\mathrm{L}_{9}$ orthogonal array is kept empty for the error of experiments. For calculation of Signal-to-noise ratio, Taguchi suggests the smaller-the-better characteristics $(\mathrm{dB})$ which is expressed as $\mathrm{S} / \mathrm{N}_{\mathrm{LB}}=-10 \log _{10}\left(1 / \mathrm{r} \Sigma \mathrm{Pz}^{2}\right)$ where Pz is the value of cutting force for the $i^{\text {th }}$ test in that trial. Similarly, $\mathrm{S} / \mathrm{N}$ ratio for chip reduction coefficient $(\zeta)$ is calculated using smaller-the-better characteristics. Table 3 shows the experimental results and their corresponding $\mathrm{S} / \mathrm{N}$ ratio values for cutting force $(\mathrm{Pz})$ and chip reduction coefficient $(\zeta)$ respectively.

\section{Table 1}

Process parameters and their levels

\begin{tabular}{lccccc}
\hline Parameters & Notation & Unit & \multicolumn{3}{c}{ Levels of factors } \\
& & & Level 1 & Level 3 \\
\hline Cutting speed & $\mathrm{v}$ & $\mathrm{m} / \mathrm{min}$ & 22 & 35 & 55 \\
Feed & $\mathrm{f}$ & $\mathrm{mm} / \mathrm{rev}$ & 0.05 & 0.1 & 0.2 \\
Depth of cut & $\mathrm{d}$ & $\mathrm{mm}$ & 0.4 & 0.6 & 0.8 \\
\hline
\end{tabular}

Table 2

Experimental layout using Taguchi $\mathrm{L}_{9}\left(3^{3}\right)$ orthogonal array

\begin{tabular}{cccc}
\hline Cutting speed & Feed & Depth of cut & Error \\
\hline 1 & 1 & 1 & \\
1 & 2 & 2 & \\
1 & 3 & 3 \\
2 & 1 & 3 \\
2 & 2 & 1 \\
2 & 3 & 2 \\
3 & 1 & 2 \\
3 & 2 & 3 \\
\hline 3 & 3 & 1 & \\
\hline
\end{tabular}


Table 3

Experimental results and corresponding $\mathrm{S} / \mathrm{N}$ ratios for $\mathrm{Pz}$ and $\zeta$

\begin{tabular}{cccccccc}
\hline Run & $\mathrm{v}$ & $\mathrm{f}$ & $\mathrm{d}$ & $(\mathrm{Pz}), \mathrm{N}$ & $\mathrm{S} / \mathrm{N}(\mathrm{Pz})$ & $\zeta$ & $\mathrm{S} / \mathrm{N}(\zeta)$ \\
\hline 1 & 22 & 0.05 & 0.4 & 90 & -39.084 & 5.4 & -14.647 \\
2 & 22 & 0.1 & 0.6 & 140 & -42.922 & 1.5 & -3.521 \\
3 & 22 & 0.2 & 0.8 & 370 & -51.364 & 1.65 & -4.349 \\
4 & 35 & 0.05 & 0.8 & 140 & -42.922 & 2.2 & -6.848 \\
5 & 35 & 0.1 & 0.4 & 130 & -42.278 & 1.9 & -5.575 \\
6 & 35 & 0.2 & 0.6 & 240 & -47.604 & 1.15 & -1.213 \\
7 & 55 & 0.05 & 0.6 & 50 & -33.979 & 1.8 & -5.105 \\
8 & 55 & 0.1 & 0.8 & 290 & -49.247 & 1.3 & -2.278 \\
9 & 55 & 0.2 & 0.4 & 190 & -45.575 & 1.85 & -5.343 \\
\hline
\end{tabular}

\section{Optimization of individual performance characteristics}

In this section, results of the orthogonal turning experiments are studied by using the $\mathrm{S} / \mathrm{N}$ ratio. From the results of signal-to-noise ratio, optimal combination of process parameters for individual performance characteristics including cutting force and chip reduction coefficient are obtained and verified. The optimization of individual performance characteristics is described below.

\subsection{Optimal process parameter for cutting force $(\mathrm{Pz})$}

Results of the machining experiments are studied by using the signal-to-noise ratio. Based on the results of the $\mathrm{S} / \mathrm{N}$ and main effect plot, optimal process parameters for surface roughness are obtained and verified. Taguchi method suggests the equation for calculating the $\mathrm{S} / \mathrm{N}$ ratio for smaller-the-better characteristics (in $\mathrm{dB})$ is

$\mathrm{S} / \mathrm{N}_{\mathrm{SB}}=-10 \log _{10}\left(\frac{1}{n} \sum_{i=1}^{n} y_{i}^{2}\right)$

where $\mathrm{y}$ is the value of surface roughness for the $i^{\text {th }}$ test in that trial.

Table 3 shows the experimental results and $\mathrm{S} / \mathrm{N}$ ratio for cutting force. In the signal-to-noise ratio, Taguchi expressed signal as desirable value and noise being undesirable value. The highest $\mathrm{S} / \mathrm{N}$ ratio always yields optimum process parameter with minimum variance. The $\mathrm{S} / \mathrm{N}$ ratio for each parameter level is calculated by averaging the $\mathrm{S} / \mathrm{N}$ ratios at the corresponding level for cutting force. Table 4 shows the response table for $\mathrm{S} / \mathrm{N}$ ratio of cutting force obtained for different parameter levels. From the main effect plot (Fig. 2); highest $\mathrm{S} / \mathrm{N}$ ratio is obtained at level-3 for cutting speed, level-1 for feed and level-2 for depth of cut respectively. Therefore, the optimal combination of process parameter is found to be $\mathrm{v} 3-\mathrm{fl}-\mathrm{d} 2$.

It is also revealed that, the feed is the most influencing parameter on cutting force followed by depth of cut confirmed through main effect plot and ranking from mean response table of S/N. Cutting speed is found to be least significant from the study. After identifying the optimal parameters, the next step is to verify and predict the improvement of cutting force for which a confirmation run is conducted. The estimated $\mathrm{S} / \mathrm{N}$ ratio using the optimal combination of cutting parameters has been calculated according to Nalbant (2007). From the verification Table 5, it is seen that, the improvement of $\mathrm{S} / \mathrm{N}$ ratio from initial cutting parameters to optimal cutting parameters is $10.103 \mathrm{~dB}$. Also, it is evident from verification test result that, the cutting force is decreased 3.2 times and is greatly improved. 
Table 4

Response table of mean $\mathrm{S} / \mathrm{N}$ ratio for cutting force

\begin{tabular}{cccc}
\hline Level & $\mathrm{v}$ & $\mathrm{f}$ & $\mathrm{d}$ \\
\hline 1 & -44.46 & -38.66 & -42.31 \\
2 & -44.27 & -44.82 & -41.5 \\
3 & -42.93 & -48.18 & -47.84 \\
$\Delta(\max -\min )$ & 1.52 & 9.52 & 6.34 \\
Rank & 3 & 1 & 2 \\
\hline
\end{tabular}

Total mean $\mathrm{S} / \mathrm{N}$ ratio $=-43.886$

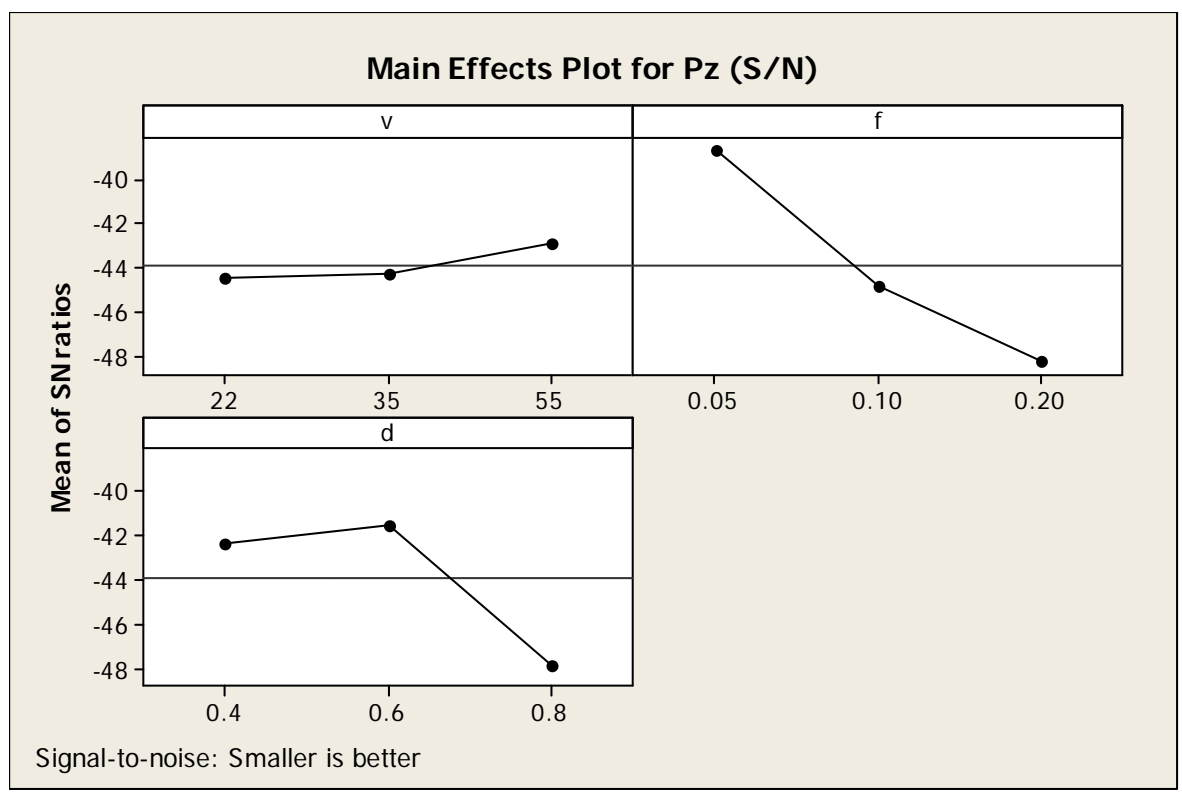

Table 5

Fig. 2. Main effect plot for cutting force $(\mathrm{Pz})$

Results of the verification experiment for cutting force

\begin{tabular}{lccc}
\hline & Initial cutting parameters & \multicolumn{2}{c}{ Optimal cutting parameters } \\
& & Prediction & Experiment \\
\hline Level & $\mathrm{v} 2-\mathrm{f} 2-\mathrm{d} 2$ & $\mathrm{v} 3-\mathrm{f} 1-\mathrm{d} 2$ & $\mathrm{v} 3-\mathrm{f} 1-\mathrm{d} 2$ \\
Cutting force, $\mathrm{Pz}(\mathrm{N})$ & 160 & & 50 \\
$\mathrm{~S} / \mathrm{N}$ ratio $(\mathrm{dB})$ & -44.082 & -35.318 & -33.979 \\
\hline Improvement of $\mathrm{S} / \mathrm{N}$ ratio & \multicolumn{3}{c}{10.103} \\
\hline
\end{tabular}

\subsection{Optimal process parameter for chip reduction coefficient (ל)}

Similar procedure has been adopted to get the optimum parametric combination for chip reduction coefficient. Table 6 shows the response table for $\mathrm{S} / \mathrm{N}$ ratio of chip reduction coefficient obtained for different parameter levels. From the main effect plot (Fig. 3), highest $\mathrm{S} / \mathrm{N}$ ratio is obtained at level-3 for cutting speed, level-3 for feed and level-2 for depth of cut respectively. Therefore, the optimal combination of process parameter is found to be v3-f3-d2. From main effect plot and ranking obtained from Table 6, it is evident that, depth of cut is the most influencing parameter on chip reduction coefficient followed by feed. Cutting speed is found to be insignificant from the study. From the verification Table 7, it is seen that, the improvement of $\mathrm{S} / \mathrm{N}$ ratio from initial cutting parameters to optimal cutting parameters is $0.869 \mathrm{~dB}$. Also, it is evident from verification test result that, the chip reduction coefficient is decreased 1.1 times and is greatly improved. 
Table 6

Response table of mean $\mathrm{S} / \mathrm{N}$ ratio for chip reduction coefficient

\begin{tabular}{cccc}
\hline Level & $\mathrm{v}$ & $\mathrm{f}$ & $\mathrm{d}$ \\
\hline 1 & -7.506 & -8.867 & -8.522 \\
2 & -4.546 & -3.792 & -3.28 \\
3 & -4.243 & -3.636 & -4.492 \\
$\Delta(\max -\min )$ & 3.264 & 5.232 & 5.242 \\
Rank & 3 & 2 & 1 \\
\hline
\end{tabular}

Total mean $\mathrm{S} / \mathrm{N}$ ratio $=-5.431$

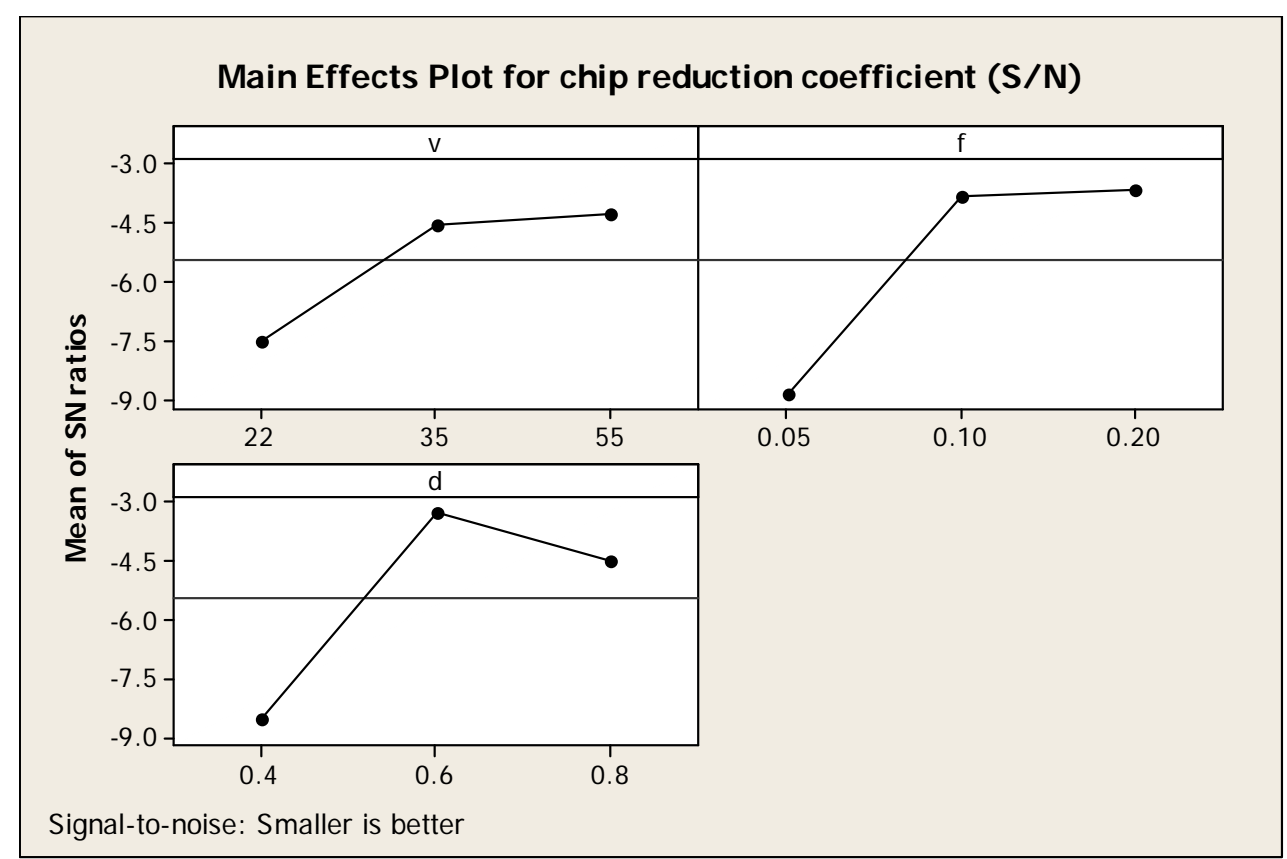

Table 7

Fig. 3. Main effect plot for chip reduction coefficient

Results of the verification experiment for chip reduction coefficient

\begin{tabular}{cccc}
\hline & Initial cutting parameters & \multicolumn{2}{c}{ Optimal cutting parameters } \\
& & Prediction & Experiment \\
\hline Level & v2-f2-d2 & v3-f3-d2 & v3-f3-d2 \\
Chip reduction coefficient, $\zeta$ & 2.1 & & 1.9 \\
S/N ratio $(\mathrm{dB})$ & -6.444 & -0.297 & -5.575 \\
\hline
\end{tabular}

Improvement of $\mathrm{S} / \mathrm{N}$ ratio

0.869

\section{Optimization of multiple performance characteristics}

For simultaneous optimization of cutting force and chip reduction coefficient, multi-response signal-tonoise ratio is computed. For this, the loss function is calculated based on lower-the-better performance characteristics. Then the loss function for each performance characteristics is normalized. Different weighting method is used to determine the importance of each normalized loss function. For this, three cases are considered based on different weightage. In case 1, weightage of cutting force and chip reduction coefficient is given as 7 and 3 respectively. In case 2, the weightage for cutting force and chip reduction coefficient is taken as 3 and 7 . For case 3, equal weightage is given to both responses as 5. The total loss function is calculated based on weighting method and then transformed to multiresponse signal-to-noise ratio (MRSN) shown in Table 8. Then, mean multi-response table is computed at each level of process parameters. Mean MRSN for cutting speed at level 1, 2 and 3 is obtained by averaging the multi-response $\mathrm{S} / \mathrm{N}$ ratios for the experiments 1-3, 4-6 and 7-9 respectively. For other 
level of process parameters, similar approach is adopted. Mean MRSN for different cases are shown in Table 9, 10 and 11 respectively. Figs. 3-5 show the main effect plot for mean multi-response S/N graph for case 1,2 and 3 respectively. The optimal combination of process parameter is chosen based on larger mean multi-response S/N ratios. Therefore, from main effect plot (Fig. 4) \& Table 9, the optimal process parameter for case 1 are the cutting speed at level 3, feed at level 1 and depth of cut at level 2 i.e. v3-f1-d2. Similarly, the optimal process parameter for case 2 and case 3 are found to be cutting speed at level 3, feed at level 2 and depth of cut at level 2 i.e. v3-f2-d2. For case 1, depth of cut is found to be most significant parameter followed by feed which is seen from Figure 4 and Table 9. Also from the Figure 5 and 6, it is concluded that, depth of cut is the most dominant parameter followed by cutting speed for case 2 and 3 respectively.

Table 8

Multi-response $\mathrm{S} / \mathrm{N}$ ratio (MRSN) with different weighting factors

\begin{tabular}{llll}
\hline Experiment No. & \multicolumn{2}{c}{ Multi-response S/N ratio (dB) } \\
& Case-1 & Case-2 & \multicolumn{2}{c}{ Case-3 } \\
& $\mathrm{w} 1=7, \mathrm{w} 2=3$ & $\mathrm{w} 1=3, \mathrm{w} 2=7$ & $\mathrm{w} 1=5, \mathrm{w} 2=5$ \\
\hline 1 & -12.149 & -15.529 & -14.16 \\
2 & -6.43 & -6.122 & -6.278 \\
3 & -13.805 & -11.128 & -12.669 \\
4 & -7.584 & -8.583 & -8.112 \\
5 & -6.675 & -7.435 & -7.071 \\
6 & -10.084 & -7.532 & -8.992 \\
7 & -3.18 & -6.106 & -4.885 \\
8 & -11.691 & -9.024 & -10.559 \\
\hline & -8.878 & -8.245 & -8.573 \\
\hline
\end{tabular}

Table 9

Mean multi-response S/N table for case-1 (w $1=7$, w2 = 3)

\begin{tabular}{llcccc}
\hline Symbol & Process parameter & \multicolumn{4}{c}{ Mean multi-response S/N ratio (dB) } \\
& & Level-1 & Level-2 & Level-3 & Max-Min \\
\hline v & Cutting speed & -10.794 & -8.114 & -7.916 & 2.878 \\
f & Feed & -7.637 & -8.265 & -10.922 & 3.285 \\
d & Depth of cut & -9.234 & -6.564 & -11.026 & 4.462 \\
\hline
\end{tabular}

Total mean multi-response $\mathrm{S} / \mathrm{N}$ ratio $=-8.941$

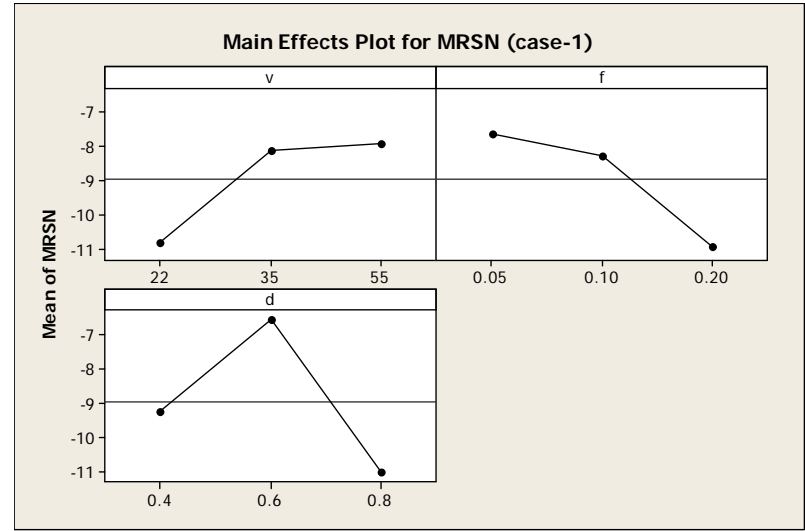

Fig. 4. Main effect plot for MRSN (case-1)

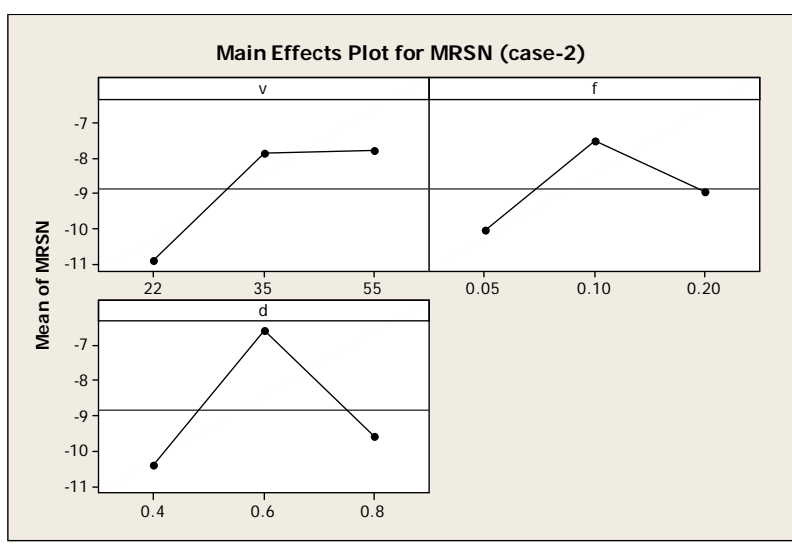

Fig. 5. Main effect plot for MRSN (case-2) 
Table 10

Mean multi-response S/N table for case-2 (w 1 = 3, w2 =7)

\begin{tabular}{llcccc}
\hline Symbol & Process parameter & \multicolumn{4}{c}{ Mean multi-response S/N ratio (dB) } \\
& & Level-1 & Level-2 & Level-3 & Max-Min \\
\hline v & Cutting speed & -10.926 & -7.85 & -7.791 & 3.135 \\
$\mathrm{f}$ & Feed & -10.072 & -7.527 & -8.968 & 2.545 \\
$\mathrm{~d}$ & Depth of cut & -10.403 & -6.586 & -9.578 & 3.817 \\
\hline
\end{tabular}

Total mean multi-response $\mathrm{S} / \mathrm{N}$ ratio $=-8.856$

Table 11

Mean multi-response S/N table for case-3 (w $1=5$, w2 = 5)

\begin{tabular}{llllll}
\hline Symbol & Process parameter & \multicolumn{4}{l}{ Mean multi-response $\mathrm{S} / \mathrm{N}$ ratio $(\mathrm{dB})$} \\
& & Level-1 & Level-2 & Level-3 & Max-Min \\
\hline v & Cutting speed & -11.035 & -8.058 & -8.005 & 3.03 \\
$\mathrm{f}$ & Feed & -9.052 & -7.969 & -10.078 & 2.109 \\
$\mathrm{~d}$ & Depth of cut & -9.934 & -6.718 & -10.446 & 3.728 \\
\hline
\end{tabular}

Total mean multi-response $\mathrm{S} / \mathrm{N}$ ratio $=-9.033$

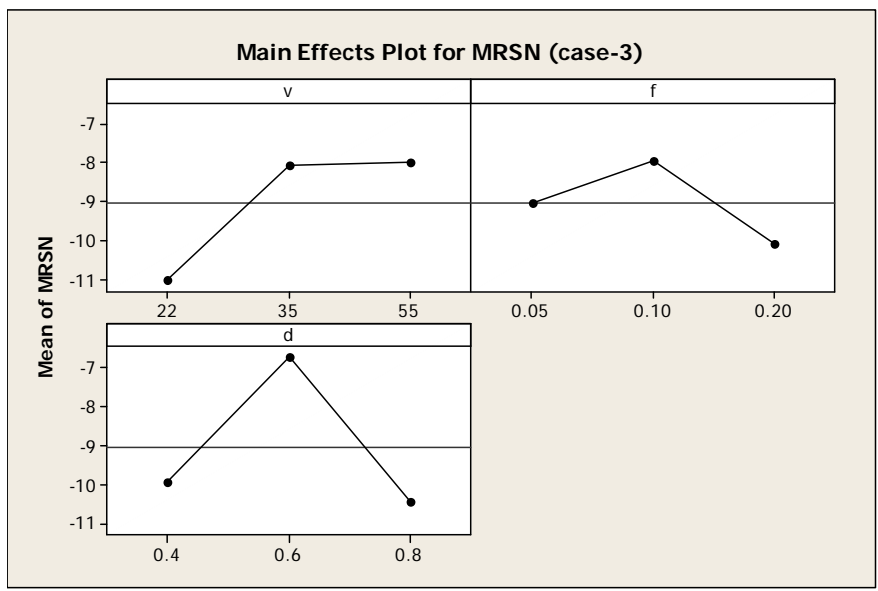

Fig. 6. Main effect plot for MRSN (case-3)

\subsection{Confirmation tests}

After optimal process parameters are identified, the next step is to predict and verify the improvement of responses. The predicted $\mathrm{S} / \mathrm{N}$ ratio for optimal combination of process parameter is obtained using Eq. 6.

$\hat{\eta}=\eta_{m}+\sum_{i=1}^{q}\left(\overline{\eta_{i}}-\eta_{m}\right)$

where $\eta_{m}$ is the mean total mean of the multi-response $\mathrm{S} / \mathrm{N}$ ratio, $\eta_{i}$ is the mean of multi-response $\mathrm{S} / \mathrm{N}$ ratio at the optimal level and $q$ is the number of process parameters.

The results of the confirmation experiment for case 1, 2 and 3 are shown in Table 12, 13 and 14 respectively. The improvement of multi-response $\mathrm{S} / \mathrm{N}$ ratio from initial process parameter to optimal process parameter are found to be $4.952 \mathrm{~dB}$ for case $1,2.405 \mathrm{~dB}$ for case 2 and $2.056 \mathrm{~dB}$ for case 3 respectively and greatly improved through this approach. From the confirmation test, cutting force is decreased by 3.2 times because of largest weighting factor and chip reduction coefficient is decreased by 1.17 times taking case 1 into consideration. Therefore, the performance of turning operation is improved significantly utilizing case 1 . Similarly, the cutting force and chip reduction coefficient is 
decreased by $1.15 \& 1.17$ times for case 2 and case 3 respectively. Once again, the machining performance is greatly improved.

Table 12

Results of the confirmation experiment for case-1 (w $1=7, \mathrm{w} 2=3$ )

\begin{tabular}{llll}
\hline & Initial process parameters & \multicolumn{2}{c}{ Optimal process parameters } \\
& & Prediction & Experiment \\
\hline Level & $\mathrm{v} 2-\mathrm{f} 2-\mathrm{d} 2$ & $\mathrm{v} 3-\mathrm{f} 1-\mathrm{d} 2$ & $\mathrm{v} 3-\mathrm{f} 1-\mathrm{d} 2$ \\
Cutting force, $\mathrm{Pz}(\mathrm{N})$ & 160 & & 50 \\
Chip reduction coefficient, $\zeta$ & 2.1 & -4.235 & 1.8 \\
S/N ratio $(\mathrm{dB})$ & -8.132 & & -3.18 \\
\hline
\end{tabular}

Improvement multi-response $\mathrm{S} / \mathrm{N}$ ratio $=4.952 \mathrm{~dB}$

Table 13

Results of the confirmation experiment for case- 2 (w $1=3$, w2 $=7$ ) Initial process parameters Optimal process parameters

\begin{tabular}{llll} 
& & Prediction & Experiment \\
\hline Level & v2-f2-d2 & v3-f2-d2 & v3-f2-d2 \\
Cutting force, $\mathrm{Pz}(\mathrm{N})$ & 160 & & 140 \\
Chip reduction coefficient, $\zeta$ & 2.1 & & 1.5 \\
S/N ratio $(\mathrm{dB})$ & -8.527 & -4.192 & -6.122 \\
\hline
\end{tabular}

Improvement multi-response $\mathrm{S} / \mathrm{N}$ ratio $=2.405 \mathrm{~dB}$

Table 14

Results of the confirmation experiment for case-3 (w $1=5, \mathrm{w} 2=5$ ) Initial process parameters Optimal process parameters

\begin{tabular}{llll} 
& & Prediction & Experiment \\
\hline Level & v2-f2-d2 & v3-f2-d2 & v3-f2-d2 \\
Cutting force, $\mathrm{Pz}(\mathrm{N})$ & 160 & & 140 \\
Chip reduction coefficient, $\zeta$ & 2.1 & & 1.5 \\
S/N ratio (dB) & -8.334 & -4.626 & -6.278 \\
\hline
\end{tabular}

Improvement multi-response $\mathrm{S} / \mathrm{N}$ ratio $=2.056 \mathrm{~dB}$

\section{Conclusions}

The methodology of Taguchi optimization for multi-objective problem using quality loss function is utilized and studied. In order to demonstrate the potential of the proposed methodology, a case study of minimizing cutting force and chip reduction coefficient during turning of mild steel is presented. The investigation follows the specific conclusions.

1. Basically, cutting force and chip reduction coefficient are strongly correlated with cutting parameters such as cutting speed, feed rate, and depth of cut. Hence, optimization of the cutting parameters based on the parameter design of the Taguchi method is adopted in this paper.

2. The optimal combination of process parameter is found to be $\mathrm{v} 3-\mathrm{f} 1-\mathrm{d} 2$ for cutting force. It is also revealed that, the feed is the most influencing parameter on cutting force followed by depth of cut.

3. From the verification test, the improvement of $\mathrm{S} / \mathrm{N}$ ratio from initial cutting parameters to optimal cutting parameters is $10.103 \mathrm{~dB}$ for cutting force. In addition, the cutting force is decreased 3.2 times and is greatly improved. 
4. The optimal level of process parameter for chip reduction coefficient is found to be v3-f3-d2. Depth of cut is the most influencing parameter on chip reduction coefficient followed by feed.

5. The improvement of $\mathrm{S} / \mathrm{N}$ ratio is found to be $0.869 \mathrm{~dB}$. Also, the chip reduction coefficient is decreased 1.1 times and is greatly improved noticed from verification test.

6. For multi-response optimization, the optimal process parameter for case 1 is found to be v3-f1-d2. Similarly, the optimal process parameter for case 2 and case 3 is v3-f2-d2.

7. The improvement of multi-response $\mathrm{S} / \mathrm{N}$ ratio from initial process parameter to optimal process parameter are found to be $4.952 \mathrm{~dB}$ for case $1,2.405 \mathrm{~dB}$ for case 2 and $2.056 \mathrm{~dB}$ for case 3 respectively and greatly improved through this approach.

8. It is concluded that the Taguchi method and quality loss function provides a simple, systematic and efficient methodology for the optimization of the individual and multiple performance characteristics.

\section{References}

Aggarwal, A., Singh, H., Kumar, P., \& Singh, M. (2008). Optimizing power consumption for CNC turned parts using response surface methodology and Taguchi's technique-A comparative analysis. Journal of materials processing technology, 200, 373-384.

Davim, J. P. (2001). A note on the determination of optimal cutting conditions for surface finish obtained in turning using design of experiments. Journal of materials processing technology, 116, 305-308.

Davim, J. P. (2003) Design of optimization of cutting parameters for turning metal matrix composites based on the orthogonal arrays. Journal of materials processing technology, 132, 340-344.

Daniel Kirby, E., Zhang, Z., Chen, J. C., \& Chen, J. (2006). Optimizing surface finish in a turning operation using the Taguchi parameter design method. International Journal of Advanced Manufacturing Technology, 30, 1021-1029.

Dhar, N. R., Kamruzzaman, M., \& Mahiuddin, A. (2006). Effect of minimum quantity lubrication (MQL) on tool wear and surface roughness in turning AISI-4340 steel. Journal of materials processing technology, 172, 299-304.

Gauri, S. K., \& Chakraborty, S. (2009). Multi-response optimization of WEDM process using principal component analysis. International Journal of Advanced Manufacturing Technology, 41, 741-748.

Jayant, A. (2008) Prediction of surface roughness in CNC turning operation using Taguchi design of experiments. IE (I)-PR, 88, 19-25.

Nalbant, M., Gökkaya, H., \& Sur, G. (2007). Application of Taguchi method in the optimization of cutting parameters for surface roughness in turning. Materials and Design, 28, 1379-1385.

Palanikumar, K. (2006). Cutting parameters optimization for surface roughness in machining of GFRP composites using Taguchi's Method. Journal of Reinforced Plastics and Composites, 25(16), 17391751.

Phadke, M. S. (1989). Quality engineering using robust design. Englewood Cliffs. NJ: Prentice-Hall.

Piispannen, V. (1948). Theory of formation of metal chips. Journal of Applied Physics, 19(10), 876.

Ross, P. J. (1988). Taguchi Techniques for Quality Engineering. McGraw- Hill, New York.

Singh, H., \& Kumar, P. (2006). Optimizing feed force for turned parts through the Taguchi Technique. Sadhana. 31(6), 671-681.

Sukthomya, W., \& Tannock, J. (2005). The optimisation of neural network parameters using Taguchi's design of experiments approach: an application in manufacturing process modelling. Neural Computing \& Applications, 14(4), 337-344.

Taguchi, G. (1990). Introduction to Quality Engineering. Asian Productivity Organization, Tokyo.

Tosun, N., Ozler, L. (2004). Optimisation for hot turning operations with multiple performance characteristics. International Journal of Advanced Manufacturing Technology, 23, 777-782.

Yang, J. L., \& Chen, J. C. (2001). A systematic approach for identifying optimum surface roughness performance in end-milling operations. Journal of industrial technology, 17(2), 1-8. 